\title{
ARTICLE
}

\section{Iron deficiency in children}

\author{
R Thejpal, MB ChB, FCPaed (SA), Cert Clin Haematology (SA) \\ Department of Paediatrics and Child Health, Faculty of Health Sciences, University of KwaZulu-Natal, Durban, South Africa
}

Corresponding author: R Thejpal (thejpal@ukzn.ac.za)

A search (MEDLINE/PubMed) was conducted of recent and relevant articles on iron deficiency in childhood. Iron deficiency remains a global health problem. In South Africa, multiple interventions, including mandatory fortification and a programme for deworming and supplementation, have significantly reduced the prevalence of anaemia. Studies continue to show that iron deficiency in infancy and early childhood is associated with negative neurocognitive, motor and behavioural effects, some of which persist despite treatment. Maternal iron deficiency has negative effects during pregnancy and in the postpartum period, which affects maternal health (e.g. depression, stress, interaction) and has negative effects on the baby (e.g. behavioural and immunological effects).

Newer tests include the soluble transferrin receptor, reticulocyte haemoglobin and hepcidin assays. The hepcidin level is useful in differentiating iron deficiency from anaemia of chronic disease with and without iron deficiency. Screening is a challenge and no firm recommendations have been made. The mainstay of treatment remains oral iron (commonly ferrous sulphate). Failure to respond to treatment, refractory iron deficiency and use of parenteral iron are briefly covered.

S Afr Med J 2015;105(7):607. DOI:10.7196/SAMJnew.7781

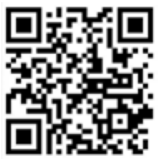

Anaemia is a worldwide health problem affecting developed and developing countries. Children $<5$ years of age and women of child-bearing age are the most vulnerable. Iron deficiency anaemia (IDA) ranked 15th and 14th in the global disability-adjusted life-years in 1990 and 2010, respectively. ${ }^{[1]}$ Globally, the prevalence of anaemia was $32.9 \%$ in $2010 .{ }^{[2]}$ Anaemia contributed to $8.8 \%$ of the total disability from all conditions. Although the prevalence of anaemia has decreased since 1990, it has increased in children $<5$ years of age during this period; the poorest countries have an unacceptably high prevalence. Anaemia in childhood is defined as a haemoglobin $(\mathrm{Hb})$ concentration below cutoff levels established by the World Health Organization: $<11 \mathrm{~g} / \mathrm{dL}$ in children aged 6 - 59 months, $<11.5 \mathrm{~g} / \mathrm{dL}$ in children aged $5-11$ years and $<12 \mathrm{~g} / \mathrm{dL}$ in children aged $12-14$ years. Causes of anaemia vary by age, sex and geographical region, but IDA remains the leading cause of anaemia worldwide. Regions with a high prevalence of anaemia (Asia and subSaharan Africa) have a larger burden of infections and iron deficiency.

In childhood, anaemia is more prevalent in boys owing to parasite infestation, mainly hookworm. In adults, anaemia is more prevalent and severe in women. High-income regions have a higher incidence of anaemia caused by haemoglobinopathy, chronic kidney disease and gastrointestinal haemorrhage. In sub-Saharan Africa, malaria is a major cause $(24.7 \%)$ of anaemia. Almost half of the world's anaemia burden is caused by iron deficiency. ${ }^{[3,4]}$ IDA represents the extreme end of the spectrum of iron deficiency and a large burden of iron deficiency without anaemia is present in the background. In South Africa (SA), the prevalence of anaemia in children $<5$ years of age has decreased by approximately $63 \%$ since $2005 .{ }^{[5]}$

\section{Iron physiology}

Iron is a major component of the earth's crust and an essential element for all living organisms in an oxygen-rich environment. Environmental iron exists as ferric iron $\left(\mathrm{Fe}^{3+}\right)$ or ferrous iron $\left(\mathrm{Fe}^{2+}\right)$. Ferric iron is almost insoluble in water at a neutral $\mathrm{pH}$, and as a polar hydrophilic ion is unable to cross membranes. Iron can readily convert from one form to the other $\left(\mathrm{Fe}^{2+}\right.$ and $\left.\mathrm{Fe}^{3+}\right)$ by losing or gaining an electron. This is useful in all reactions requiring the loss or gain of electrons, but potentially toxic when reactive oxygen species are generated.
Iron is required for many metabolic processes, such as oxygen transport, drug metabolism, as a cofactor for essential enzymatic reactions (including synthesis of steroid hormones and neurotransmitters), cellular respiration, electron transport within cells, DNA synthesis, gene regulation and cell proliferation and differentiation.

\section{Iron absorption and distribution}

Three pathways exist in enterocytes for the uptake of food iron Haem iron and non-haem iron are absorbed into the enterocyte non-competitively. Haem is maintained in a soluble state and digested enzymatically free of globin. Haem enters the enterocyte as a metalloporphyrin. Within the cell, iron is released from haem by haem oxygenase to pass into the body as inorganic iron. Most non-haem dietary iron is ferric iron. Some ferric iron enters the absorptive cell via the integrin-mobilferrin pathway. Iron is reduced in the gut lumen by the action of duodenal cytochrome $b$ or ferric reductase and enters the enterocyte via the divalent metal transporter-1 (DMT-1).

The DMT- 1 is found mainly at the apical surface of the enterocytes of the first part of the duodenum, in endodermal vesicles in erythroid and other cells and on macrophages. DMT-1 also transports zinc, copper, cobalt, manganese, cadmium and lead. Ferroportin (basolateral transporter) in association with hephaestin (ferroxidase) is responsible for iron export from cells (enterocytes, placenta, macrophages and hepatocytes).

Absorption varies with iron stores (stores regulator), erythroid activity (erythropoietic regulator), tissue iron deficiency and changes in mucosal oxygen tension. The enterocyte is informed of body requirements for iron and programmed accordingly at the base of the crypt. Intracellular ferritin controls the amount of iron retained by the cell and excess iron is stored as ferritin to protect the cell from oxidative damage. Iron leaves the enterocyte via the ferroportin transporter. Transferrin is the receiving protein that transports iron in the plasma.

Severe IDA results in a marked increase in erythropoiesis. Inadequate haemoglobinisation results in ineffective erythropoiesis, as these cells are not viable and an increase occurs in effective iron turnover and the serum transferrin receptor.

More than two-thirds of the body's iron $(28-30 \mathrm{mg} / \mathrm{kg})$ is in $\mathrm{Hb}$ and myoglobin $(5 \mathrm{mg} / \mathrm{kg})$. The remainder is storage iron ferritin $(4-8 \mathrm{mg} / \mathrm{kg})$, haemosiderin $(2-4 \mathrm{mg} / \mathrm{kg})$ and iron bound to transferrin $(<1 \mathrm{mg} / \mathrm{kg})$. 
Losses, approximately $1-2 \mathrm{mg}$ daily (skin, menses), need to be balanced by intestinal absorption of $1-2 \mathrm{mg}$ daily.

Hepcidin is a key protein in iron homeostasis. ${ }^{[6,7]}$ Intra- and extracellular iron concentrations and infection/inflammation increase the hepcidin concentration, while increased erythropoiesis suppresses hepcidin production. Hepcidin regulates plasma iron by its effect on ferroportin concentrations in the enterocyte, macrophage and hepatocyte. Elevated hepcidin levels in anaemia associated with infection, inflammation, chronic kidney disease and cancer cause down-regulation of the ferroportin exporter and sequestration of iron in the enterocyte, hepatocyte and macrophage. In IDA, hepcidin levels are suppressed to low or undetectable levels.

\section{Sources of iron}

Haem iron, which is readily available for absorption, is found in clams, oysters, liver and red meat. In the USA and Europe, most of the dietary iron is from haem. Non-haem iron is mainly available from vegetables and is less bioavailable. Sources are fortified cereals, beans, soya, spinach, lentils and asparagus. The presence of haem iron, vitamin $\mathrm{C}$ or citrus juice in the diet enhances absorption of dietary iron. Eggs, soya, bran, phytates, phosphates, tannates, oxalates, carbonates and other iron chelators reduce absorption of dietary iron. Rice is a poor source of dietary iron.

\section{Causes of iron deficiency anaemia in childhood}

In adults about $95 \%$ of the iron required for new red cell $\mathrm{Hb}$ is recycled from aged red cells and only $5 \%$ comes from the diet. Because infants grow so rapidly, $<70 \%$ of iron is recycled and $30 \%$ is required from dietary sources. Factors contributing to the development of iron deficiency include ante- and perinatal factors that influence infant iron status, increased iron requirements for the expanding red cell mass during growth, and blood loss. Women of reproductive age are at risk because of menstruation, fetal and placental requirements, and bleeding during delivery. Children of anaemic mothers are a vulnerable group. Maternal iron deficiency is associated with increased maternal and infant mortality; it also influences birth weight and duration of gestation in mothers of low birth weight or premature infants.

\section{Millk feeds and iron deficiency}

The dietary iron requirement of infants up to 6 months of age has been estimated at $0.27 \mathrm{mg} /$ day; the iron in breastmilk is adequate for most babies. Breastmilk iron is bioavailable and up to $50 \%$ of the ingested iron is absorbed. Iron stores are depleted when the baby doubles its birth weight. Children $6-12$ months of age require $11 \mathrm{mg} /$ day, which is not met by breastmilk. The iron requirement decreases to $7 \mathrm{mg}$ /day between the ages of $1-3$ years, an amount that may be readily supplied by the introduction of iron-rich foods. ${ }^{[8]}$ Exclusive breastfeeding, without supplementation, beyond 6 months is a risk factor for IDA. Iron in cow's milk and formula milk is poorly absorbed. Formula feeds are therefore suitably fortified. However, the use of undiluted cow's milk and a predominant cow's milk intake in later infancy is associated with IDA. Contributory factors are allergy and proportionately less intake of weaning feeds containing iron.

Iron stores are directly proportional to birth weight, i.e. low birth weight babies have lower iron stores at birth and are at increased risk of IDA. Infants of diabetic mothers, babies with a low cord ferritin level and twin and multiple pregnancies are also at risk.

\section{Impact of postpartum maternal iron deficiency}

Maternal anaemia has been observed to be significantly related to postpartum depression and fatigue. ${ }^{[9]} \mathrm{A}$ conservative estimate of anaemia in adult women in an urban SA environment is $15 \%\left(10 \%\right.$ IDA). ${ }^{[10]}$
Maternal iron deficiency is associated with impaired cognition and interaction and mother-child interaction is negatively affected. The potential child health risks associated with maternal anaemia and iron deficiency may not be limited to the prenatal period. In HIV, anaemia and iron deficiency are common and independent predictors of HIV disease progression and mortality. Maternal anaemia in the postpartum period strongly predicted child mortality and immune status in children born to HIV-infected women. ${ }^{[11,12]}$

\section{Iron deficiency anaemia in infancy}

Iron deficiency can impair growth and intellectual development. Iron has been documented to have an effect on normal myelination and basal ganglia function. The brain is most vulnerable during rapid brain growth, especially in the third trimester of pregnancy and the first 2 years of life. Iron deficiency, even without anaemia, can result in neuropsychological effects and has been linked to cognitive impairment in later childhood and in adolescence. ${ }^{[13]}$ Iron deficiency in infants resulted in poorer motor function. ${ }^{[14]}$ Infants with iron deficiency test lower in cognitive, motor, social-emotional and neurophysiological development than controls. Of concern is the occurrence of motor defects in non-anaemic infants with iron deficiency, persistence of some of these defects and failure to consistently improve with iron therapy. ${ }^{[15]}$

Iron deficiency affects cell-mediated immunity and myeloperoxidase activity in phagocytes. It has also been reported to increase susceptibility to common infections. Some patients with life-threatening infections received 'vigorous iron therapy'. ${ }^{[16]}$ The defect in cell-mediated immunity corrects with iron therapy. Fungal infections, herpes, other viral infections and repeated bacterial infections have been reported. Treatment of iron deficiency may predispose to the development of malaria in certain settings. Maternal IDA was associated with significantly lower CD4 counts in exposed but uninfected babies. ${ }^{[12]}$

Iron deficiency has effects on epithelial surfaces. Glossitis, stomatitis, oesophageal webs and malabsorption reflect direct involvement of the gastrointestinal tract; pica and koilonychia may also be present.

\section{Prevention and treatment}

There is no ideal age for the screening of children. At any given point there would be infants who are anaemic for a period, while others would become anaemic thereafter. A number of countries in sub-Saharan Africa, India and Afghanistan have 'an alarmingly high level of hidden hunger, with stunting, iron deficiency anaemia and vitamin A deficiency all being highly prevalent. ${ }^{[17]}$ These numbers are likely to increase with economic recession and climate change, and other poverty-related factors will result in inequalities in early childhood development. The effects prenatally and in the first year of life will have long-lasting negative consequences on intellectual development and motor functioning. ${ }^{[18]}$ There is a real need for multiple micronutrient interventions (e.g. iron, zinc, vitamin A) to tackle this hidden burden of disease. To ameliorate iron deficiency, fortified supplementary foods, deworming and prophylactic iron treatment are indicated. In SA, mandatory food fortification (iron, zinc, vitamin A, thiamine, riboflavin and vitamin $B_{6}$ ) was introduced in 2003 for maize and wheat flour. Furthermore, a national programme to provide deworming and school feeding has been implemented. Additional intervention with a micronutrient-fortified beverage reduced iron deficiency (based on serum ferritin) from $29.2 \%$ to $5.5 \%{ }^{[19]}$ In this study, improvement in cognitive test scores was also documented. Baseline prevalence of anaemia improved from $27.9 \%$ to $5.8-8.8 \%$ in the different groups.

\section{Prophylaxis}

Prophylaxis is indicated for high-risk groups, including low birth weight and premature babies, infants of diabetic mothers, exclusively breastfed infants (especially beyond 6 months of age), babies who 
Table 1. Intravenous iron preparations

\begin{tabular}{|c|c|c|c|c|}
\hline Preparation & $\begin{array}{l}\text { Iron sucrose } \\
\text { (Venofer) }\end{array}$ & $\begin{array}{l}\text { LMW iron dextran } \\
\text { (CosmoFer) }\end{array}$ & $\begin{array}{l}\text { Ferric carboxymaltose } \\
\text { (Ferinject) }\end{array}$ & $\begin{array}{l}\text { Iron isomaltose } \\
\text { (Monofer) }\end{array}$ \\
\hline Test dose & Required & Required & No & No \\
\hline $\begin{array}{l}\text { Dosage and } \\
\text { administration }\end{array}$ & $\begin{array}{l}\text { Maximum: } 200 \mathrm{mg} \text { in } \\
30 \text { minutes } 3 \text { times } \\
\text { a week }\end{array}$ & $\begin{array}{l}100 \text { - } 200 \text { mg in } 30 \text { minutes } \\
2 \text { - } 3 \text { times a week } \\
\text { TDI } 4 \text { - } 6 \text { hours }\end{array}$ & $\begin{array}{l}\text { TDI or } 15 \mathrm{mg} / \mathrm{kg} \text { slow } \\
\text { intravenous injection } \\
100 \mathrm{mg} / \mathrm{min} \text { injection } \\
\text { Up to } 1000 \mathrm{mg} \text { in } 15 \text { minutes }\end{array}$ & $\begin{array}{l}200 \text { - } 1000 \mathrm{mg} \text { once weekly } \\
200 \mathrm{mg} \text { in } 4 \text { minutes } \\
\text { TDI over } 60 \text { minutes }\end{array}$ \\
\hline Contraindications & $\begin{array}{l}\text { Drug hypersensitivity, } \\
\text { asthma, atopy, } \\
\text { pregnancy }\end{array}$ & $\begin{array}{l}\text { Drug hypersensitivity, asthma, } \\
\text { atopy, cirrhosis, renal failure, } \\
\text { infection, rheumatoid arthritis } \\
\text { (active) }\end{array}$ & Drug hypersensitivity & $\begin{array}{l}\text { Drug hypersensitivity, } \\
\text { asthma, atopy, cirrhosis, } \\
\text { rheumatoid arthritis }\end{array}$ \\
\hline Cost & Cheap & Cheaper & More expensive & Expensive \\
\hline
\end{tabular}

are introduced to cow's milk early, and in multiple pregnancies and peripartum blood loss. The requirement for prophylaxis for premature and low birth weight babies is higher. The suggested iron intake for term infants is $1 \mathrm{mg} / \mathrm{kg}$ body weight per day to a maximum of $15 \mathrm{mg}$, starting no later than 4 months and continuing until 3 years of age. The recommendation for low birth weight infants is $2 \mathrm{mg} / \mathrm{kg} /$ day to a maximum of $15 \mathrm{mg}$, starting no later than 2 months of age. Delayed cord clamping is advocated. In older children there is a place for intermittent prophylaxis (once or twice a week).

\section{Presentation and diagnosis}

Presentation with severe anaemia is easily recognised, as these patients have pallor, a high cardiac output state and are sometimes in cardiac failure. Irritability, fatigue, poor concentration, gastrointestinal effects, pica and koilonychia may be present. Microcytosis and anaemia $(\mathrm{Hb}<11.5 \mathrm{~g} / \mathrm{dL})$ are the most severe stages of deficiency. Confirmatory tests include low serum iron (there may be a diurnal variation), elevated transferrin and transferrin saturation $<16 \%$. A low serum ferritin is confirmatory (at all ages $<10-12 \mu \mathrm{g} / \mathrm{mL}$ ), but elevation occurs with inflammation, infection and liver disease. The challenge is to detect patients with subclinical or latent iron deficiency, without anaemia (stage 1, where stores are depleted, and stage 2, where iron transport for erythropoiesis is decreased). Tests include serum ferritin $(<15 \mu \mathrm{g} / \mathrm{L})$, soluble transferrin receptor concentration $(>8.3 \mathrm{mg} / \mathrm{L})$ and zinc protoporphyrin concentration $(>70 \mu \mathrm{mol} / \mathrm{mol}$ haem). Zinc protoporphyrin is also affected by inflammation and lead poisoning. The newer tests (soluble transferrin receptor and reticulocyte $\mathrm{Hb}$ content) have not added much to diagnosing iron deficiency.

The hepcidin assay has promise in diagnosing pure IDA (low levels) from anaemia of chronic disease (ACD) or combined IDA/ $\mathrm{ACD}$, where the levels are higher. The assessment of stainable iron on bone marrow smear or biopsy for the definitive diagnosis of IDA is still widely regarded as the gold standard, but reliability is suboptimal.

Because of the high prevalence of dietary iron deficiency, it is justified to diagnose IDA by a therapeutic trial of iron treatment. A baseline $\mathrm{Hb}$ is done and $5-6 \mathrm{mg} / \mathrm{kg} /$ day elemental iron is administered. Systemic improvement occurs within days, the reticulocyte response peaks at $5-10$ days (roughly $10 \%$ ), $\mathrm{Hb}$ increases with $1-2 \mathrm{~g}$ in the first 3 weeks and $\mathrm{Hb}$ and smear normalise in 2 months, irrespective of severity. A failed trial requires further testing to confirm the diagnosis and aetiology. Failure to respond to oral iron may be owing to failure to take medication, discontinuation of medication, persisting blood loss, infection, missed diagnosis (malabsorption, ACD), misdiagnosis of or accompanying folate deficiency.
The preferred treatment is with oral iron for a further 2 - 3 months after the $\mathrm{Hb}$ normalises to replenish stores. Concomitant vitamin $\mathrm{C}$ enhances absorption. The medication is ideally taken on an empty stomach. Side-effects (nausea, vomiting, diarrhoea, heartburn) can be reduced by administering the treatment with meals, dose modification or a change in preparation.

\section{Indications for parenteral iron}

Refractory IDA requires exclusion of bowel pathology (coeliac disease, gastritis, Helicobacter pylori infection, bleeding) and often an endoscopic examination is indicated. True malabsorption is rare, but rapid transit times and failure to absorb enteric-coated tablets may occur. Moreover, oral iron intolerance, poor compliance, kidney disease with erythropoietin, bowel disease and ongoing blood loss are indications for parenteral iron. Various intravenous preparations are available (Table 1). The more expensive preparations enable total dose infusions within an hour.

\section{References}

1. Murray CIL, Lopez AD. Measuring the global burden of disease. N Engl J Med 2013:169:448-457. [http://dx.doi.org/10.1056/NEJMra1201534]

2. Kassebaum NJ, Jasrasaria R, Naghavi M, et al. A systematic analysis of global anemia burden from 1990 to 2010. Blood 2014;123(5):615-624. [http://dx.doi.org/10.1182/blood-2013-06-508325]

World Health Organization (WHO)/UNICEF/UNU. Iron Deficiency Anaemia: Assessment, Prevention, and Control. A Guide for Programme Managers. Geneva:WHO, 2001.

4. Pasricha S-R, Drakesmith H, Black J, et al. Control of iron deficiency anemia in low- and middleincome countries. Blood 2013;121(14):2607-2617. [http://dx.doi.org/10.1182/blood-2012-09-453522] Shisana O, Labadarios D, Rehle T, et al. South African National Health and Nutrition Examination Survey (SANHNES-1). Cape Town: HSRC Press, 2013.

6. Ganz T, Nemeth E. Hepcidin and iron homeostasis. Biochim Biophys Acta 2012;1823:1434-1443. [http://dx.doi.org/10.1016/j.bbamcr.2012.01.014]

7. Theuri I, Aigner E, Theuri M, et al. Regulation of iron homeostasis in anemia of chronic disease and iron deficiency anemia: Diagnostic and therapeutic implications. Blood 2009;113:5277-5286. [http:// dx.doi.org/10.1182/blood-2008-12-195651]

8. Baker RD, Greer FR. Diagnosis and prevention of iron deficiency and iron-deficiency anemia in infants and young children ( 0 - 3 years of age). Pediatrics 2010;126:1040-1050. [http://dx.doi.org/10.1542/peds 2010-2576]

Corwin EJ Muray

J Nutr 2003;133:4139-4132.
I J J Nutr 2003;133:4139-4132.

( Glencross DK. Iron deficiency anaemia in healthy South African women despite iron fortification. S Afr Med J 2008;98(8):606-607.

1. Levine AM, Berhane K, Masri-Lavine L, et al. Prevalence and correlates of anemia in a large cohort of HIV infected women: Women's Interagency HIV Study. J Acquir Immune Defic Syndr 2001;26:28-35. 2. Isanaka S, Spiegelman D, Aboud S. Post-natal anaemia and iron deficiency in HIV-infected women and the health and survival of their children. Matern Child Nutr 2012;8(3):287-298. [http://dx.doi org/10.1111/j.1740-8709.2011.00389.x]

3. Grantham-McGregor S, Ani C. A review of studies on the effect of iron deficiency on cognitive development in children. J Nutr 2001;131:649S-648S.

4. Shafir T, Angulo-Barrosa R, Jing Y, et al. Iron deficiency and motor development. Early Hum Dev 2008;84:479-485. [http://dx.doi.org/10.1016/j.earlhumdev.2007.12.009]

15. Lozoff B, Georgieff MK. Iron deficiency and brain development. Semin Pediatr Neurol 2006;13:158-165. 16. Cook JD, Lynch SR. The liabilities of iron deficiency. Blood 1986;68(4):803-809.

17. Muthayya S, Rah JH, Sugimoto JD, et al. The global hidden hunger indices and maps: An advocacy too Muthayya S, Rah JH, Sugimoto JD, et al. The global hidden hunger indices and maps: An ad
for action. PLoS One 2013;8(6):e67860. [http://dx.doi.org/10.1371/journal.pone.0067860]

18. Walker SP, Wachs TD, Grantham-McGregor S, et al. Inequality in early childhood: Risk and protective factors for early childhood development. Lancet 2011;378:1325-1338. [http://dx.doi.org/10.1016/ S0140-6736(11)60555-2]

19. Taljaard C, Covic NM, van Graan AE, et al. Effects of a multi-micronutrient-fortified beverage, with and without sugar, on growth and cognition in South African schoolchildren: A randomised, double-blind, controlled intervention. Br J Nutr 2013;110: 2271-2284. [http://dx.doi.org/10.1017 S000711451300189X] 